\title{
Urbanization alters small rodent community composition but not abundance
}

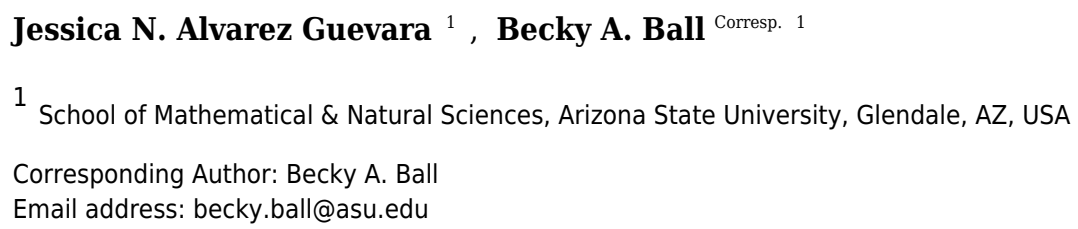

Desert ecosystems are one of the fastest urbanizing areas on the planet. This rapid shift has the potential to alter the abundances and species richness of herbivore and plant communities. Herbivores, for example, are expected to be more abundant within urban desert remnant parks located within cities due to anthropogenic activities that concentrate food resources and reduce native predator populations. Despite this assumption, previous research conducted around Phoenix, AZ, USA has shown that top-down herbivory led to equally reduced plant biomass in both urban and outlying locations. It is unclear if this insignificant difference in herbivory at urban and outlying sites is due to unaltered desert herbivore populations or altered activity levels that counteract abundance differences. Small rodent herbivore/granivore populations were surveyed at four sites inside and four sites outside of the core of Phoenix during fall 2014 and spring 2015 in order to determine whether abundances and richness differ significantly between urban and rural sites. In order to survey species composition and abundance at these sites, 100 Sherman traps and 8 larger wire traps that are designed to attract and capture small vertebrates such as mice, rats, and squirrels were set at each site for two consecutive trap nights. Results suggest that the commonly assumed effect of urbanization on herbivore abundances does not apply to small rodent populations in a desert city, as overall small rodent abundances were statistically similar regardless of location. Though a significant difference was not found for species richness, a significant difference between small rodent genus richness at these sites was observed, with altered community composition. The compositional differences likely reflect the altered vegetative community and may impact ecological interactions at these sites. 
1 Urbanization alters small rodent community composition but not abundance

2

3 Jessica N. Alvarez Guevara ${ }^{\mathrm{a}}$ and Becky A. Ball ${ }^{* a}$

4

5 a School of Mathematical and Natural Sciences, Arizona State University at the West Campus:

64701 W Thunderbird Rd, Glendale, AZ 85306 USA. Becky.Ball@asu.edu.

7 * Corresponding author

8

9 Corresponding author:

10 Becky A. Ball

11 School of Mathematical and Natural Sciences

12 Arizona State University at the West Campus

$134701 \mathrm{~W}$. Thunderbird Rd.

14 Glendale, AZ 85306

15 becky.ball@asu.edu

16 phone: +001 (602) 543-2010 


\section{ABSTRACT}

Desert ecosystems are one of the fastest urbanizing areas on the planet. This rapid shift has the potential to alter the abundances and species richness of herbivore and plant communities. Herbivores, for example, are expected to be more abundant within urban desert remnant parks located within cities due to anthropogenic activities that concentrate food resources and reduce native predator populations. Despite this assumption, previous research conducted around Phoenix, AZ, USA has shown that top-down herbivory led to equally reduced plant biomass in both urban and outlying locations. It is unclear if this insignificant difference in herbivory at urban and outlying sites is due to unaltered desert herbivore populations or altered activity levels that counteract abundance differences. Small rodent herbivore/granivore populations were surveyed at four sites inside and four sites outside of the core of Phoenix during fall 2014 and spring 2015 in order to determine whether abundances and richness differ significantly between urban and rural sites. In order to survey species composition and abundance at these sites, 100 Sherman traps and 8 larger wire traps that are designed to attract and capture small vertebrates such as mice, rats, and squirrels were set at each site for two consecutive trap nights. Results suggest that the commonly assumed effect of urbanization on herbivore abundances does not apply to small rodent populations in a desert city, as overall small rodent abundances were statistically similar regardless of location. Though a significant difference was not found for species richness, a significant difference between small rodent genus richness at these sites was observed, with altered community composition. The compositional differences likely reflect the altered vegetative community and may impact ecological interactions at these sites.

\section{INTRODUCTION}



in arid ecosystems (UNDP, 2014). In the Sonoran Desert of the southwestern United States, the Phoenix, AZ metropolitan area is one of the largest and fastest-growing metropolitan areas in the U.S., with a higher than average population growth for the past several decades (Martin \& Stabler, 2002; U.S. Census Bureau, 2015). For example, in the last 25 years, the resident population within the Phoenix metropolitan area has increased by 47\% (Davis et al., 2015) to its current 4.6 million people. As a result, the area of undisturbed land within this city alone decreased by $21 \%$ from 1985 to 2005 (Buyantuyev et al., 2010). within urban parks are often expected to be higher than those found in rural areas due to human activities that concentrate food resources and eradicate native predators (Rodewald \& Shustack, 2008; Shochat et al., 2010). Trail systems, anthropogenic water sources, surface temperature and the presence of utilities may be favored by certain species to increase their abundance in urban parks (Markovchick-Nicholls et al., 2008; Pianalto \& Yool, 2017; Rudd \& Bateman, 2015; Switalski \& Bateman, 2017). Species richness, on the other hand, is expected to decrease with urbanization (sensu McKinney, 2008; Saari et al., 2016). The homogenization of species in urban areas is often associated with habitat fragmentation and the introduction of non-native species (McKinney, 2006). Additionally, habitat fragmentation and anthropogenic activity can make areas inviable for certain fauna, and can therefore alter their distribution (Markovchick-Nicholls et al., 2008).

Alterations to the community composition of herbivorous organisms can then cause plant communities to shift (Gruner et al., 2008). It is expected that herbivores in urban areas consume and therefore reduce more above-ground plant biomass than those in rural sites due to higher 
63 abundances. Despite this assumption, previous research at the Central Arizona-Phoenix Long-

64 Term Ecological Research (CAP-LTER) has shown that herbivory within urban and rural

65 Sonoran Desert remnant parks has led to equally reduced biomass in urban and outlying areas

66 (Davis et al., 2015). It is unclear whether this lack of difference in herbivory is the result of

67 unaltered herbivore populations or different activity levels that counteract differences in

68 population densities, given the lack of published data reporting the abundance of small vertebrate

69 herbivores in and around the Phoenix metropolitan area. As urbanization continues to expand

70 and encroach onto the native land of many herbivores and plants, it is important to study and

71 understand how the lives of these herbivore species, and therefore the plants they eat, are

72 affected.

73 We quantitatively surveyed small rodent populations at four sites inside (urban) and four

74 sites outside (outlying) of the city core of Phoenix to determine whether abundances and

75 diversity differ significantly with urban activities. Small rodents (including mice, rats, and

76 squirrels) are common vertebrate herbivores, granivores, and omnivores in the Sonoran Desert,

77 which have the potential to impact plant biomass and community composition. We hypothesize

78 that overall abundance of the rodent species found within the desert remnant parks inside the city

79 will be significantly higher, and that the species richness will be significantly lower, than the

80 outlying parks located outside the core of the city of Phoenix.

81

82 MATERIALS \& METHODS

83 Study Site

84 This study was conducted within remnant parks of the Northern Sonoran Desert of Arizona. All

85 study plots are found within the $6400 \mathrm{~km}^{2}$ CAP LTER boundaries that encompass the area in and 
86 around the city of Phoenix (Davis et al., 2015). The average annual rainfall for sites within the

87 core of the city of Phoenix in $2014 \& 2015$ was $272( \pm 14) \mathrm{mm}$ and $149( \pm 4) \mathrm{mm}$, respectively,

88 while the average annual rainfall for rural sites was $300( \pm 28) \mathrm{mm}$ and $207( \pm 22) \mathrm{mm}$ in those

89 same years (FCDMC, 2009). Several uncharacteristically large storms in 2014 caused higher

90 precipitation averages than those of previous years, and 2015 was more consistent with the long-

91 term averages (Ball \& Alvarez Guevara, 2015; Davis et al., 2015). Dominant plants within the

92 Sonoran Desert ecosystem include creosote (Larrea tridentate), bursage (Ambrosia deltoidea),

93 palo verde (Cercidium spp.), and ironwood (Olneya tesota). Additional plants identified at study

94 cites include succulents, such as saguaros (Carnegiea gigantea), chain fruit cholla

95 (Cylindropuntia fulgida), and teddy bear cholla (Cylindropuntia bigelovii).

96

97

98

\section{Experimental Design}

Eight desert remnant park sites inside and outside of the city of Phoenix previously utilized for CAP LTER herbivore exclosure studies (Davis et al., 2015) were used in this population census (Figure 1). In order to directly compare the effect urbanization had on abundance and community composition of small rodents, four urban sites were sampled alongside four outlying sites. Urban sites were located inside of the city of Phoenix, while outlying sites were located to the east of the urban core.

Trapping events took place over four weekends in both the fall (September-October) of 2014 and spring (March-May) of 2015 in order to account for the fluctuation of populations associated with the seasons. These two seasons were selected because small rodents also tend to be most active during spring and fall when extreme heat and cold do not present a mortality concern (Moseley et al., 2011). A single weekend trapping event surveyed both an urban and 
109 outlying site for two consecutive nights and mornings. Coupled urban-outlying sites were kept

110 consistent in both the fall and spring, though the order in which the four paired sites were

111 surveyed in the fall were shuffled in the spring to reduce the influence of sampling order on

112 results. Trapping events were not scheduled during full moons, as previous studies indicate that

113 small rodents limit activity in order to reduce exposure to nocturnal predators (Daly et al., 1992).

114 Additionally, trapping events were not scheduled during weekends with severe weather predicted

115 (i.e. thunderstorms or temperature below $40^{\circ} \mathrm{F}$ ) in order to minimize rodent mortality risks. This

116 work was conducted under AZ Game \& Fish Scientific Collecting permits SP654186 (2014) and

117 SP694606 (2015) and IACUC protocol \#13-1316R at Arizona State University.

119 Small Rodent Surveys

120 Community composition and abundances of mice, rats, and squirrels were quantified using the

121 live capture-release method (Sikes \& ACUC, 2016). Traps were scattered within a 20,000 $\mathrm{m}^{2}$

122 area at each site and placed in key habitat types in order to ensure maximal rodent capture rates.

123 Initial trapping efforts revealed optimal trap placement to be under native plant cover such as

124 palo verde (Cercidium spp.), mesquite (Prosopis spp.), creosote (Larrea tridentate), etc. Desert

125 ecosystems are characterized by a patchy distribution of vascular plants, with exposed interplant

126 spaces between shrubs (Crawford \& Gosz, 1982; Schlesinger et al., 1996), and these interplant

127 spaces provide no source of cover or food for small plant-associated rodents (herbivores and

128 granivores in particular) that we were targeting. In fact, preliminary methods testing

129 demonstrated that traps in interplant spaces were almost entirely empty during trapping events.

130 To increase our trapping success and the likelihood of observing maximum numbers of 
131 individuals and taxa, we targeted plant-based habitat types across defined, replicated areas of the

132 Sonoran Desert, as described below.

At each site for two consecutive nights, 100 Sherman folding traps $(7.62 \times 8.89 \times 22.86$ $\mathrm{cm})$ and 8 larger wire traps $(17.78 \times 17.78 \times 17.78 \mathrm{~cm})$ were set and baited with a mix of rolled oats and toasted oat cereal, totaling 216 traps set per night across the urban-outlying site pairs.

Within the set $20,000 \mathrm{~m}^{2}$ area of each study site, four equal quadrants were visualized. Sherman

137 traps 1-25 were placed within quadrant one, Sherman traps 26-50 were placed within quadrant two, etc. Each quadrant also contained two larger wire traps. Traps were set in the late afternoon of the first and second day, and rodents were identified to species the following mornings using Kays and Wilson's Mammals of North America (Kays \& Wilson, 2002).

All traps were closed after the identification of small rodents on the first morning and were kept closed throughout the day until set and baited again that same afternoon. This was done in order to minimize trap mortality associated with the heat of the day. To target diurnal rodents, the order in which the sites were visited on the first morning was reversed on the second morning; this allowed the traps to be open for an extra 2-3 hours of daylight while data was

146 being obtained from its paired site.

\section{Data Analysis}

149 Small rodent abundance, as well as species and genera richness were analyzed using Analysis of

150 Variance (ANOVA) in R 2.7.2 (The R Foundation) with both Location (urban or rural) and 151 Season (fall or spring) as main effects, as well as their interaction. Data were found to be normal.

152 Eight sites (4 urban and 4 outlying) over 2 seasons yields 16 total samples. Abundances were 153 defined as the number of rodents captured per 100 trap nights. We do not attempt to calculate 
154 density, given that we did not place traps on a random and evenly-spaced grid system. The

155 Shannon Index for diversity $\left(\mathrm{H}=\sum p \ln (p)\right)$ and evenness $\left(\mathrm{J}^{\prime}=\mathrm{H} / \mathrm{H}_{\max }\right)$ were calculated and also

156 analyzed using ANOVA. Due to the small replication feasible in this study, we also ran a

157 nonparametric Kruskal-Wallace test on the same data, which yielded the same conclusions as the

158 ANOVA, bolstering the conclusion that are data are normal. A non-metric multidimensional

159 scaling (NMDS) was conducted using the small rodent species abundance data using the

160 metaMDS command in the package "vegan" in R, where stress is 0.0580 . A Permutational

161 Multivariate Analysis of Variance (PERMANOVA) was additionally used to test for the impacts

162 of Location*Season on community composition, also using the "vegan" package in R, using the

163 default 999 permutations. It should be noted that several individuals escaped prior to their

164 identification to species, and are therefore only known to the genus level. These data are

165 included in total abundances, but no other metrics or analyses.

167 RESULTS

Overall, total rodent abundance and species-level diversity did not differ between urban and outlying sites, but did at the genus level. Small rodent abundances were slightly higher within the urban desert remnant parks (Figure 2a), though this difference was statistically

171 insignificant (Table 1). Measures of diversity at the species level, including species richness, 172 Shannon index, and species evenness, tended to be slightly higher in the outlying sites but were 173 again not significantly different across location (Figure 2b-d, Table 1). Variation in species 174 richness within urban parks was higher because the South Mountain sites tended to be more 175 diverse than the Desert Botanical Garden and Piestewa Peak sites (standard error in Figure 2b).

176 In contrast to the lack of difference in species diversity, outlying sites outside of the city are 
177 significantly greater in genus richness than urban sites (Figure 2e, Table 1). Season and its

178 interaction with location did not significantly influence any of the measures of rodent community

179 (Table 1), so all data discussed are pooled across the year.

180 Beyond measures of diversity, community composition differed between urban and

181 outlying locations. The PERMANOVA identified a significant effect of Location on community

182 composition of species (Table 1). Certain taxa were associated with either urban or outlying sites

183 (Table S1). Deer mice (Peromyscus spp.) were only identified within the urban sites, while

184 grasshopper mice (Onychomys spp.) and kangaroo rats (Dipodomys spp.) were only identified at

185 outlying park sites. Further, the NMDS shows a separation of urban and outlying sites, with all

186 outlying parks grouping together in the upper left-to-central portion of the ordination and urban

187 parks on the lower right-to-central portion (Figure 3). This difference is driven by the higher

188 abundances of certain species at outlying parks, such as white-throated woodrats (Neotoma

189 albigula) and Merriam's kangaroo rats (Dipodomys merriami; Table S1). Within the outlying

190 sites, the McDowell Mountain Regional Park (MCN) rodent community differed from Usery

191 Mountain Regional Park (UMP) and Salt River Recreation (SRR) in that it contained northern

192 grasshopper mice (Onychomys leucogaster). The Lost Dutchman State Park (LDP) rodent

193 community differed in that it contained a relatively high abundance of Mexican woodrats

194 (Neotoma mexicana) in comparison to UMP and SRR.

The NMDS also shows that the Desert Botanical Garden (DBG) and Piestewa Peak

(PWP) differ from the South Mountain West (SMW) and South Mountain East (SME) sites in

197

terms of small rodent species community composition. The Desert Botanical Garden site is

mainly composed of Bailey's (Chaetodipus baileyi) and desert (C. penicillatus) pocket mice 
199 (Table S1, Figure 3), while Piestewa Peak is the only site in which round-tailed ground squirrels

200 (Xerospermophilus tereticaudus) were captured.

201

202 DISCUSSION

203 Small rodent species richness, community composition, and abundance were measured in both

204 urban and outlying desert remnant parks in order to assess the impact of urbanization. We

205 hypothesized that overall small rodent abundances measured within urban desert remnant parks

206 would be higher than overall abundances of small rodents found within outlying desert remnant

207 parks. According to the data, however, the commonly assumed difference in abundance between

208 urban and outlying parks does not apply to small rodent populations in a desert city when

209 manicured environments are excluded. This supports the previous study that did not find a

210 significant difference in aboveground plant biomass consumption when comparing urban and

211 outlying desert remnant parks (Davis et al., 2015). A recent meta-analysis also shows that, across

212 ecosystems and terrestrial animal taxa considered, there is not a general trend of increased

213 abundance with urbanization (Saari et al., 2016). In fact, contrary to the common assumption, the

214 authors found evidence for decreased abundance in urban areas, though this effect became

215 insignificant when outlier European studies involving arthropods were removed. Our data

216 demonstrate that Sonoran Desert rodents are a further example of an ecosystem and taxa that do

217 not fit the generalization that urbanization increases abundance.

218 We also hypothesized that species richness would be higher in outlying parks, though this

219 was not found to be the case. The insignificant difference between the Shannon Index and

220 evenness support this finding, indicating that the urban and outlying parks sampled have similar

221 levels of diversity and evenness at the species level. These results further support the conclusions 
222 of the meta-analysis by Saari et al. (2016), which also showed statistically insignificant

223 differences in species richness with urbanization across studies. However, the meta-analysis did

224 not look at community composition beyond species richness, and in our study genus richness

225 was found to be statistically greater at outlying parks. This, along with the PERMANOVA and

226 NMDS results, means that the community composition of the small vertebrate rodents do differ

227 across site location. .

228 There are many potential mechanisms that would result in the decreased diversity (sensu

229 Saari et al., 2016), including habitat loss in the urban setting. It's possible that the plant

230 communities upon which small rodents are dependent determine which parks they inhabit. For

231

232

233

234

235

236

237

238

239

240

241

242

243

244

example, it is possible that rodent richness and diversity is the result of the diversity of the local plant community. Previous studies have shown that these outlying desert remnant parks have a more diverse plant community than urban remnant parks (Davis et al., 2015). Though both urban and outlying desert parks are dominated by Curvenut Combseed (Pectocarya recurvata), Arabian Schismus (Schismus arabicus), and Indian Plantago (Plantago ovata), the average plant percent coverage of these species is higher at outlying parks (Davis et al., 2015). Higher percent coverage of certain shrubs may lead to higher small rodent abundances, as they can provide both food and shelter (Tietje et al., 2008).

\section{The significant difference of genus richness observed between urban and outlying sites} highlights that pocket mice genera dominate urban sites, specifically Bailey's (Chaetodipus baileyi), desert (C. penicillatus), rock (C. intermedius), and Arizona (Perognathus amplus) pocket mice. Of these rodents, Bailey's, rock, and desert pocket mice are classified under the genus Chaetodipus. This may indicate homogenization of small rodents within urban parks, as closely related species tend to have similar ecological roles (Cavender-Bares et al., 2009). For 
245 example, the desert pocket mouse is known to larder hoard, which involves caching their food

246 resources in a single burrow. Merriam's Kangaroo Rats, on the other hand, are known to scatter

247 hoard their food resources in shallow pits (Leaver \& Daly, 2001). These different behaviors

248 could influence plant communities, given that the caching behavior of pocket mice, for example,

249 can influence seed germination and invasive grass establishment (Sommers \& Chesson, 2016;

250 Walker et al., 2015).

251 Some species were not identified at the outlying sites used in this study, though it is

252 important to note that these species may be present at these outlying sites at low abundances.

253 These species include the White-Footed (Peromyscus leucopus), North American (P.

254 maniculatus), and Cactus Deer Mice (P. eremicus). Previous studies have shown that this genus

255 may be able to flourish in urban desert remnant parks because their population dynamics are not

256 significantly affected by the moderate removal of shrub cover and food resources, indicating that

257 they may not have a preference in terms of storing food in the open or under shrub cover

258 (Parmenter \& MacMahon, 1983).

259 Similarly, certain species were only identified at outlying sites. Merriam's Kangaroo Rats

260 (Dipodomys merriami), for example, were found in all four outlying sites, but were not identified

261 at any of the urban sites. Merriam's kangaroo rats have been found to prefer to pilfer seed caches

262 located under shrub cover (Swartz et al., 2010). This may be why they were found at higher

263 abundances within sites that contain higher plant percent coverage. Previous studies suggest that

264 removal of kangaroo rat species (Dipodomys spp.) leads to a significant increase in abundances

265 of other seed-eating rodents such as pocket mice (Chaetodipus and Perognathus spp.) and deer

266 mice (Peromyscus spp.) species due to decreased interspecific competition pressures (Brown \&

267 Munger, 1985) and can influence plant communities (Curtin et al., 2000). 

outlying McDowell Mountain site. These species, like pocket and deer mice, are not significantly affected by the moderate removal of plant cover (Parmenter \& MacMahon, 1983). The location

271 of this species may therefore be dependent on additional vital resources offered within the McDowell site. Grasshopper Mice differ from the other mice identified in that their diet almost exclusively consists of arthropods, especially during the summer months (Hope \& Parmenter, 2007). According to the diversity-trophic structure hypothesis, arthropod richness is influenced by plant richness (Knops et al., 1999). This may therefore contribute to a higher richness of insects of particular import to grasshopper mice survival at outlying parks. and diversity between disturbed urban and undisturbed locations. However, our data did not fully support the hypothesis, given that abundance did not differ between our urban and outlying sites. In this study, outlying sites were defined as areas with lower levels of disturbance when compared to urban sites that were located within the city of Phoenix. Our outlying sites are of low-to-intermediate levels of anthropogenic disturbance, which in comparison to other truly undisturbed sites would be expected to have higher levels of abundance. As such, abundances measured at the much less disturbed Cave Creek Bajada were found to be lower than those observed within the rural parks of this study (Brown \& Zeng, 1989). Another possible reason our results were not in line with generalized patterns like the intermediate disturbance hypothesis is 287 that our sampling design of targeting particular habitats for trap placement biased our results towards plant-associated species of interest. This bias was replicated across locations, so should not compromise the observed differences between locations. It is possible, though, that the 
290 intermediate disturbance hypothesis would be supported if we had surveyed the entire

291 population, rather than plant-associated species.

292 In summary, neither small rodent abundance nor species richness differed significantly

293 between urban and outlying desert remnant parks in this study. Genus richness, however, was

294 found to be significantly higher within the outlying sites, indicating that small rodent community

295 composition differs between these urban and outlying sites. It is important to further research the

296 impacts small rodents can have on desert remnant parks and the plant communities within.

297 Certain activities of these species have been linked to an increase in biodiversity and landscape

298 heterogeneity (Davidson \& Lightfoot, 2006). Food storage mounds and underground tunnels

299 made by Banner-tailed Kangaroo Rats, for example, can lead to nitrogen and phosphate rich

300 patches of soil that are preferred habitat for some desert plants (Eldridge et al., 2009). The

301 presence of small rodents can therefore be important indicators of the health of a desert remnant

302 park.

303

304 CONCLUSION

305 In sum, our results suggest that the commonly assumed effect of urbanization on herbivore

306 abundances does not apply to small rodent populations in this desert city, as overall small rodent

307 abundances were statistically similar regardless of location. Urban activity did, however,

308 influence community composition and diversity. Though a significant difference was not found

309 for species richness, a significant difference between small rodent genus richness at these sites

310 was observed, and certain taxa were specifically associated with either urban or outlying

311 locations. The compositional differences likely reflect the altered vegetative community and may

312 impact ecological interactions at these sites. 


\section{ACKNOWLEDGEMENTS}

315 We thank the AZG\&F Dept. for lending us traps during our preliminary research, and the 316 management team for each of the city, regional, and state parks used for access to the sites. 317 Lastly, we would like to give a special thanks to the following family, friends, and volunteers 318 that provided invaluable assistance in data collection: Miguel A. Alvarez, Maria M. Alvarez 319 Guevara, Miguel Alvarez Guevara, Martha Alvarez, Kelly Bergin, Sean Hosier, Miranda Vega, 320 Connor Wetzel-Brown, Ivan Fernandez, Jordan Patterson, Lexi Lake, Gabie Santos, Yesenia 321 Rodriguez-Sanchez, Sungho Park, Cesar Ruiz, Uffe Nielsen, Marcia Denmark, and Paige Smith. 
322

323

324

325

326

327

328

329

330

331

332

333

334

335

336

337

338

339

340

341

342

343

344

345

346

347

348

349

350

351

352

353

354

355

356

357

358

359

360

361

362

363

364

365

366

367

368

\section{REFERENCES}

Ball BA, and Alvarez Guevara J. 2015. The nutrient plasticity of moss-dominated crust in the urbanized Sonoran Desert. Plant and Soil 389:225-235.

Brown JH, and Munger JC. 1985. Experimental Manipulation of a Desert Rodent Community: Food Addition and Species Removal. Ecology 66:1545-1563.

Brown JH, and Zeng Z. 1989. Comparative Population Ecology of Eleven Species of Rodents in the Chihuahuan Desert. Ecology 70:1507-1525.

Buyantuyev A, Wu J, and Gries C. 2010. Multiscale analysis of the urbanization pattern of the Phoenix metropolitan landscape of USA: Time, space and thematic resolution. Landscape and Urban Planning 94:206-217.

Cavender-Bares J, Kozak KH, Fine PVA, and Kembel SW. 2009. The merging of community ecology and phylogenetic biology. Ecology Letters 12:693-715.

Crawford CS, and Gosz JR. 1982. Desert ecosystems: Their resources in space and time. Environmental Conservation 9:181-195.

Curtin CG, Kelt DA, Frey TC, and Brown JH. 2000. On the role of small mammals in mediating climatically driven vegetation change. Ecology Letters 3:309-317.

Daly M, Behrends PR, Wilson MI, and Jacobs LF. 1992. Behavioural modulation of predation risk: moonlight avoidance and crepuscular compensation in a nocturnal desert rodent, Dipodomys merriami. Animal Behaviour 44:1-9.

Davidson AD, and Lightfoot DC. 2006. Keystone rodent interactions: prairie dogs and kangaroo rats structure the biotic composition of a desertified grassland. Ecography 29:755-765.

Davis MK, Cook EM, Collins SL, and Hall SJ. 2015. Top-down vs. bottom-up regulation of herbaceous primary production and composition in an arid, urbanizing ecosystem. Journal of Arid Environments 116:103-114.

Eldridge DJ, Whitford WG, and Duval BD. 2009. Animal disturbances promote shrub maintenance in a desertified grassland. Journal of Ecology 97:1302-1310.

FCDMC. 2009. Rainfall information. Available at http://www.fcd.maricopa.gov/index.aspx.

Gruner DS, Smith JE, Seabloom EW, Sandin SA, Ngai JT, Hillebrand H, Harpole WS, Elser JJ, Cleland EE, Bracken MES, Borer ET, and Bolker BM. 2008. A cross-system synthesis of consumer and nutrient resource control on producer biomass. Ecology Letters 11:740-755.

Hope AG, and Parmenter RR. 2007. Food Habits of Rodents Inhabiting Arid and Semi-arid Ecosystems of Central New Mexico. Special Publication of the Museum of Southwestern Biology.

Kays RW, and Wilson DE. 2002. Mammals of North America: Princeton University Press.

Knops JMH, Tilman D, Haddad NM, Naeem S, Mitchell CE, Haarstad J, Ritchie ME, Howe KM, Reich PB, Siemann E, and Groth J. 1999. Effects of plant species richness on invasion dynamics, disease outbreaks, insect abundances and diversity. Ecology Letters 2:286-293.

Leaver LA, and Daly M. 2001. Food caching and differential cache pilferage: a field study of coexistence of sympatric kangaroo rats and pocket mice. Oecologia 128:577-584.

Markovchick-Nicholls L, Regan HM, Deutschman DH, Widyanata A, Martin B, Noreke L, and Ann Hunt T. 2008. Relationships between human disturbance and wildlife land use in urban habitat fragments. Conservation Biology 22:99-109.

Martin CA, and Stabler LB. 2002. Plant gas exchange and water status in urban desert landscapes. Journal of Arid Environments 51:235-254.

McKinney ML. 2006. Urbanization as a major cause of biotic homogenization. Biological Conservation 127:247-260.

McKinney ML. 2008. Effects of urbanization on species richness: A review of plants and animals. Urban Ecosystems 11:161-176. 
402

403

404

405
Moseley WA, Cooper SM, Hewitt DG, Fulbright TE, and Deyoung CA. 2011. Effects of Supplemental Feeding and Density of White-Tailed Deer on Rodents. Journal of Wildlife Management 75:675681.

Parmenter RR, and MacMahon JA. 1983. Factors determining the abundance and distribution of rodents in a shrub-steppe ecosystem: the role of shrubs. Oecologia 59:145-156.

Pianalto FS, and Yool SR. 2017. Sonoran Desert rodent abundance response to surface temperature derived from remote sensing. Journal of Arid Environments 141:76-85.

Rodewald AD, and Shustack DP. 2008. Consumer Resource Matching in Urbanizing Landscapes: Are Synanthropic Species Over-Matching? Ecology 89:515-521.

Rudd BT, and Bateman HL. 2015. Reptile use of trails in the Phoenix Mountain parks. Herpetological Reviews 46:15-17.

Saari S, Richter S, Higgins M, Oberhofer M, Jennings A, and Faeth SH. 2016. Urbanization is not associated with increased abundance or decreased richness of terrestrial animals - dissecting the literature through meta-analysis. Urban Ecosystems 19:1251-1264.

Schlesinger WH, Raikes JA, Hartley AE, and Cross AF. 1996. On the spatial pattern of soil nutrients in desert ecosystems. Ecology 77:364-374.

Shochat E, Lerman SB, Anderies JM, Warren PS, Faeth SH, and Nilon CH. 2010. Invasion, Competition, and Biodiversity Loss in Urban Ecosystems. BioScience 60:199-208.

Sikes RS, and ACUC. 2016. 2016 Guidelines of the American Society of Mammalogists for the use of wild mammals in research and education. Journal of Mammalogy 97:663-688.

Sommers P, and Chesson P. 2016. Caching rodents disproportionately disperse seed beneath invasive grass. Ecosphere 7:e01596.

Swartz MJ, Jenkins SH, and Dochtermann NA. 2010. Coexisting desert rodents differ in selection of microhabitats for cache placement and pilferage. Journal of Mammalogy 91:1261-1268.

Switalski AB, and Bateman HL. 2017. Anthropogenic water sources and the effects on Sonoran Desert small mammal communities. PeerJ 5:e4003.

Tietje WD, Lee DE, and Vreeland JK. 2008. Survival and Abundance Of Three Species Of Mice In Relation to Density Of Shrubs and Prescribed Fire In Understory Of An Oak Woodland In California. The Southwestern Naturalist 53:357-369.

U.S. Census Bureau. 2015. 2015 Census Data. Available at https://factfinder.census.gov/faces/tableservices/jsf/pages/productview.xhtml?src=bkmk.

UNDP. 2014. World Urbanization Prospects: The 2014 Revision, Highlights (ST/ESA/SER.A/352): United Nations, Department of Economic and Social Affairs, Population Division.

Walker LR, Vrooman SS, and Thompson DB. 2015. Rodent mounds facilitate shrubs and shrubs inhibit seedlings in the Mojave Desert, USA. Journal of Arid Environments 113:95-101. 


\section{Table $\mathbf{1}$ (on next page)}

Results of the Analysis of Variance (ANOVA)

Results of the Analysis of Variance (ANOVA) analyzing rodent abundance, species and genera richness, and diversity indices, as well as of the Permutational Multivariate Analysis of Variance (PERMANOVA) analyzing rodent community composition, according to Location (urban or outlying), Season (fall or spring), and their interaction. F statistics are expressed as the value for $F$, with a subscript of the degrees of freedom (df) of the factor being tested followed by the df for the Error. 
Table 1. Results of the Analysis of Variance (ANOVA) analyzing rodent abundance, species and genera richness, and diversity indices, as well as of the Permutational Multivariate Analysis of Variance (PERMANOVA) analyzing rodent community composition, according to Location (urban or outlying), Season (fall or spring), and their interaction. F statistics are expressed as the value for $F$, with a subscript of the degrees of freedom (df) of the factor being tested followed by the df for the Error.

\begin{tabular}{|c|c|c|c|c|c|c|c|c|c|c|c|c|}
\hline & \multicolumn{2}{|c|}{ Abundance } & \multicolumn{2}{|c|}{ Species richness } & \multicolumn{2}{|c|}{ Shannon index } & \multicolumn{2}{|c|}{$\begin{array}{l}\text { Species } \\
\text { evenness }\end{array}$} & \multicolumn{2}{|c|}{ Genus richness } & \multicolumn{2}{|c|}{$\begin{array}{l}\text { Community } \\
\text { composition }\end{array}$} \\
\hline & $\mathrm{F}$ & $P$ & $\mathrm{~F}$ & $P$ & $\mathrm{~F}$ & $P$ & $\mathrm{~F}$ & $P$ & $\mathrm{~F}$ & $P$ & $\mathrm{~F}$ & $P$ \\
\hline Location & $1.986_{1,12}$ & 0.184 & $0.982_{1,12}$ & 0.341 & $2.496_{1,12}$ & 0.140 & $0.391_{1,12}$ & 0.544 & $16.615_{1,12}$ & 0.002 & $3.127_{1,12}$ & 0.027 \\
\hline Season & $0.201_{1,12}$ & 0.662 & $0.000_{1,12}$ & 1.000 & $0.228_{1,12}$ & 0.642 & $0.783_{1,12}$ & 0.394 & $0.000_{1,12}$ & 1.000 & $2.203_{1,12}$ & 0.061 \\
\hline Location:Season & $1.036_{1,12}$ & 0.329 & $1.746_{1,12}$ & 0.211 & $2.194_{1,12}$ & 0.164 & $1.084_{1,12}$ & 0.318 & $0.4615_{1,12}$ & 0.510 & $0.981_{1,12}$ & 0.428 \\
\hline
\end{tabular}




\section{Figure 1}

Map of CAP LTER study sites.

Urban sites are those found within the city core, while outlying sites are those found outside of the city core. The urban sites (circles) used in this study consist of Piestewa Peak Park (PWP), Desert Botanical Garden (DBG), and South Mountain Park East (SME) and West (SMW). The outlying sites (triangles) used in this study are Usery Mountain Regional Park (UMP), Lost Dutchman State Park (LDP), Salt River Recreation (SRR), and north McDowell Mountain Regional Park (MCN).

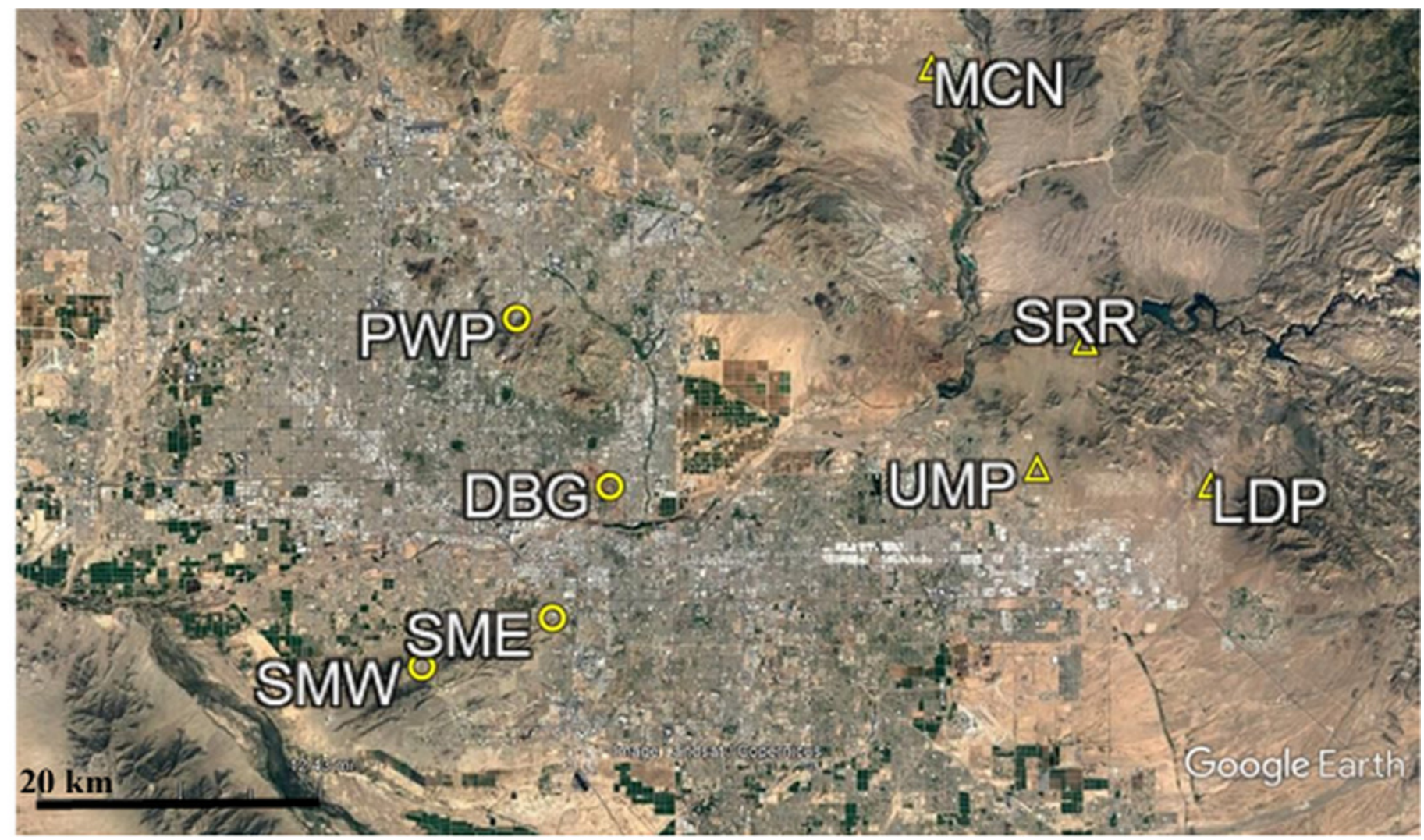


Figure 2

Small rodent community characteristics in urban and outlying sites

Small rodent community characteristics in urban and outlying sites $(n=4$, average $\pm S E)$, including (a) total abundance, (b) species richness, (c) Shannon diversity index, (d) species evenness, and (e) genus richness.
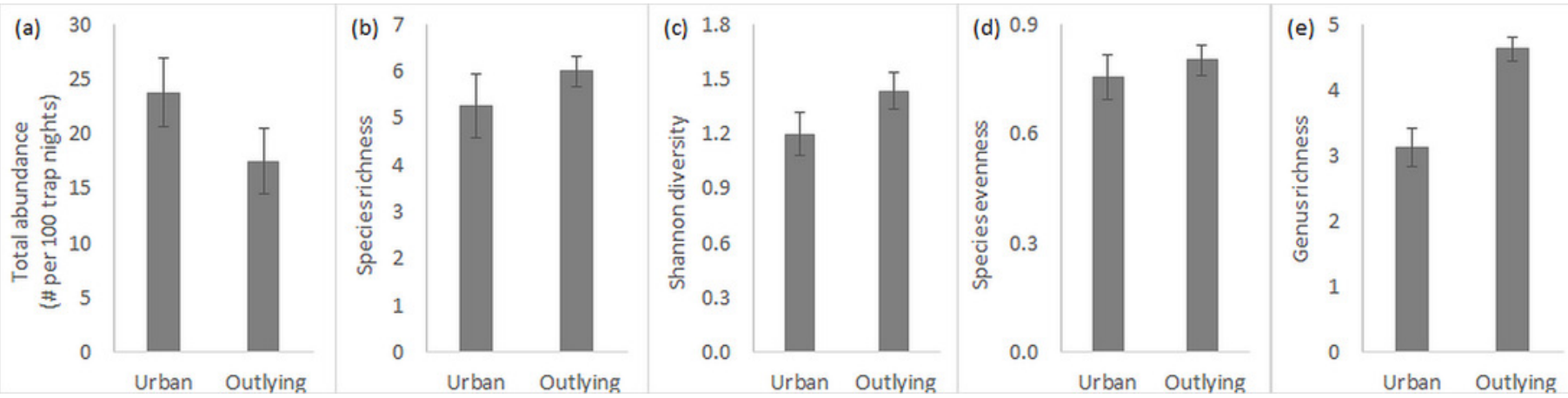


\section{Figure 3}

Non-metric multidimensional scaling (NMDS) of rodent communities found at urban and rural sites

Position of sites depends on individual abundances of species indicated by the vectors. The urban sites are Piestewa Peak Park (PWP), Desert Botanical Garden (DBG), and South Mountain Park East (SME) and West (SMW), and the rural sites are Usery Mountain Regional Park (UMP), Lost Dutchman State Park (LDP), Salt River Recreation (SRR), and north McDowell Mountain Regional Park (MCN). Species abbreviations are the first two letters of the genus and species as listed in the full species list in Appendix 1, with $P g$ being the abbreviation for Perognathus (pocket mice) and Pm being the abbreviation for Peromyscus (deer mice). Individuals that escaped prior to identification, for whom the genus is known but not the species, were left out of the analysis

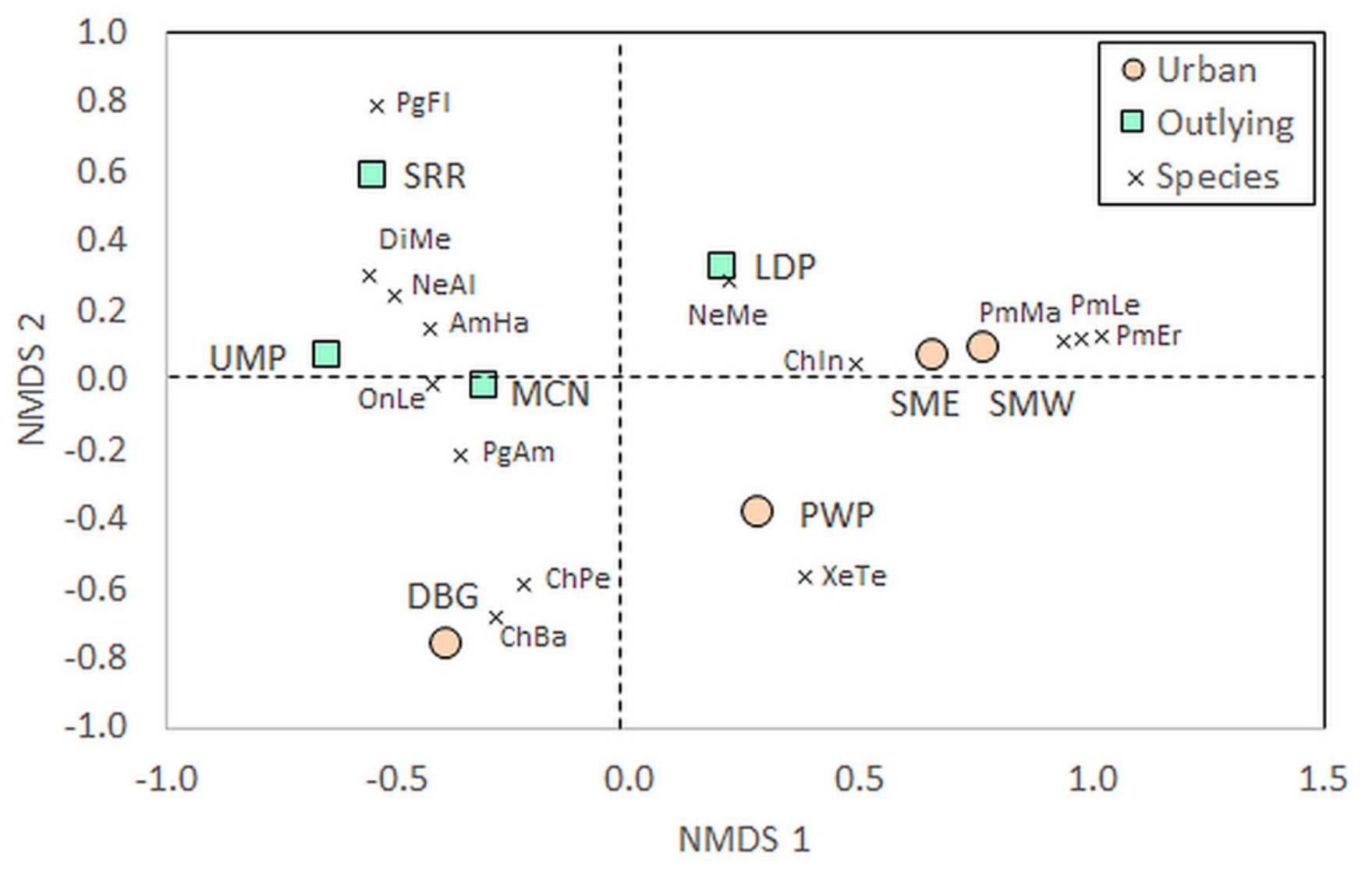

